\title{
CRESCIMENTO, PRODUÇÃO DE MATÉRIA SECA E ACÚMULO DE N, P, K, Ca, Mg E S NA PARTE AÉREA DE MUDAS DE ANDIROBA (Carapa guianensis Aubl.) CULTIVADAS EM SOLO DE VÁRZEA, EM FUNÇÃO DE DIFERENTES DOSES DE FÓSFORO ${ }^{1}$
}

Orlando Sílvio Caires Neves², Daniela da Silva Benedito², Rodrigo Villela Machado³, Janice Guedes de Carvalho $^{4}$

\begin{abstract}
RESUMO - Com o objetivo de avaliar o efeito de diferentes doses de fósforo no crescimento e produção de matéria seca e acúmulo de N, P, K, Ca, Mg e S na parte aérea de mudas de andiroba, cultivadas em solo de várzea, foi conduzido um experimento em casa de vegetação, no Departamento de Ciências do Solo (DCS) da Universidade Federal de Lavras (UFLA). O delineamento utilizado foi em blocos casualizados com cinco repetições e quatro doses de fósforo (0, 150, 300 e $450 \mathrm{mg} \mathrm{dm}^{-3} \mathrm{de}$ P). Foram avaliados diâmetro do caule $(\mathrm{mm})$, altura de plantas $(\mathrm{cm})$, matéria seca de raiz, caule, folha e total (g planta $\left.{ }^{-1}\right)$. A partir dos teores dos elementos, determinou-se o acúmulo dos nutrientes com base na matéria seca. A máxima resposta física da planta de andiroba à adubação fosfatada foi obtida na faixa de 239 a $265 \mathrm{mg} \mathrm{dm}^{-3}$ de $\mathrm{P}$. O máximo acúmulo de N, P, K, Ca, Mg e S foi atingido com as doses de 254; 287,5; 244,5; 254; 241; e 275 mg dm-3 de P, respectivamente. Os elementos em estudo que mais acumularam na parte aérea das mudas de andiroba seguem a seguinte ordem decrescente: $\mathrm{N}>\mathrm{Ca}>\mathrm{K}>\mathrm{Mg}>\mathrm{S}>\mathrm{P}$.
\end{abstract}

Palavras-chave: Andiroba, fósforo, acúmulo e solo de várzea.

\section{GROWTH, DRY MATTER YIELD AND N, P, K, CA, MG AND S ACCUMULATION IN ANDIROBA SEEDLING SHOOTS (Carapa guianensis Aubl.) CULTIVATED IN LOWLAND SOIL, IN FUNCTION OF PHOSPHORUS DOSES}

\begin{abstract}
To evaluate the effect of phosphorus application on growth, dry matter yield and $N, P, K, C a$, $M g$ and S accumulation in "andiroba" seedling shoots, cultivated in lowland soil, an experiment was conducted under greenhouse conditions at the Soil Science Department (DCS) of the Federal University of Lavras (UFLA). The experiment was conducted in a randomized block design, with five replications and four phosphorus doses $\left(0,150,300\right.$ and $450 \mathrm{mg} \mathrm{dm}^{-3}$ of P). Stem diameter $(\mathrm{mm})$, plant height $(\mathrm{cm})$, root dry matter, stem, leafs and total ( $\mathrm{g} \mathrm{plant}^{-1}$ ) were evaluated and the accumulation of the nutrients based on dry matter was determined. The maximum physical response of andiroba to phosphorus was obtained between 239 to 265 $\mathrm{mg} \mathrm{dm}^{-3}$ of P. The maximum accumulation of $\mathrm{N}, \mathrm{P}, \mathrm{K}, \mathrm{Ca}, \mathrm{Mg}$ and $\mathrm{S}$ was observed with the doses 254, 287,5, 244,5, 254, 241 and $275 \mathrm{mg} \mathrm{dm}^{-3}$ of P, respectively. The most accumulated elements in andiroba's seedling shoots followed this decreasing order: $N>C a>K>M g>S>P$.
\end{abstract}

Key words: Andiroba, phosphorus, accumulation and lowland soil.

\footnotetext{
${ }^{1}$ Recebido para publicação em 20.11.2002 e aceito para publicação em 08.6.2004

${ }^{2}$ Doutorandos em Solos e Nutrição de Plantas - Rua Sílvio Menicucci, 1510, Ap. 102, Centenário, Lavras, MG. CEP: $37200-000$ E-mail: <orlandosilvio@bol.com.br>

${ }^{3}$ Doutorando em Solos e Nutrição de Plantas - UFLA, Departamento de Ciência do Solo, Cx. Postal 37, Lavras, MG, CEP: 37200-000.

${ }^{4}$ Prof $^{a}$ Dr $^{\mathrm{a}}$ do DCS/UFLA - UFLA, Departamento de Ciência do Solo, Cx. Postal: 37, Lavras, MG, CEP: 37200-000.
} 


\section{INTRODUÇÃO}

Segundo Loureiro et al. (1979), a andiroba (Carapa guianensis Aubl.) é uma espécie que se distribui por todo o norte da América do Sul, incluindo a Bacia Amazônica, a América Central, as Antilhas e a África Tropical. No Brasil, ocorre em toda a Bacia Amazônica, principalmente em regiões de várzeas e áreas alagáveis ao longo dos igapós.

Também conhecida como andirova, angirova, carapa e purga-de-santo-inácio e pertencente à família Meliaceae (mesma do cedro e mogno), é uma árvore de grande porte, que chega a atingir $30 \mathrm{~m}$ de altura. Sua madeira é moderadamente pesada, comparável ao mogno (Swietenia macrophylla King.); de cor avermelhada e praticamente inatacável por cupins. É empregada na fabricação de móveis, construção civil e na indústria naval. Quanto ao uso medicinal, consta na literatura que, pelo menos desde a época do descobrimento, o óleo de andiroba era usado pelos índios Mundurukús como ingrediente na mumificação das cabeças dos inimigos, que serviam de troféus de guerra. Hoje, o óleo é usado principalmente como linimento contra pancadas e antiinflamatório contra dores de garganta. Pode ser usada também como matéria-prima para produção de repelente a insetos. Estima-se que o Brasil consome cerca de 30 mil litros de óleo por ano. A exportação anual é de 450 mil litros de óleo, em média. O óleo exportado atinge preço entre cinco e sete dólares o quilo. Em vários países são encontrados produtos cosméticos à base de óleo de andiroba, como cremes para o corpo e hidratantes (DELDUQUE,1999). Na Internet existem vários sites, principalmente em inglês, exaltando as qualidades da andiroba.

Em trabalhos que acompanharam o crescimento e desenvolvimento desta espécie, sob alguns tipos de manejo, solteiro e consorciado (enriquecimento) em Latossolo Amarelo (LA), Volpato et al. (1972) e Volpato et al. (1973) observaram ser esta espécie, dentre outras estudadas, a que melhor responde com crescimento satisfatório em altura, chegando a 9 e 10 m em plantios de sete (solteiro) e oito (consorciado) anos, com diâmetro à altura do peito (DAP) variando entre 13 e $8 \mathrm{~cm}$, em plantios de sete e oito anos, respectivamente.

Em avaliação feita em plantios comerciais de andiroba, em solos de diferentes texturas, nas proximidades de Manaus, AM, Magalhães et al. (1987) observaram que esta espécie apresenta maior crescimento de raízes e altura em solos com textura mais argilosa, sendo 2,5 vezes maior do que em solos arenosos, mostrando-se sensíveis a estes solos quimicamente mais pobres.

Apesar do grande interesse comercial que a madeira e o óleo de andiroba despertam no mercado, existem poucas referências na literatura sobre a nutrição mineral de mudas. Entre os poucos trabalhos, destacam-se os realizados por Martins et al. (2000a), Martins et al. (2000b), Magalhães et al. (1987), Neves et al. (2002) e Santos et al. (2002).

As várzeas são caracterizadas como áreas excessivamente úmidas, com processos químicos de redução e alta variabilidade de solos, seja sob vegetação de mata ou de campo hidrófilo (RASSINI et al.,1984). A andiroba, por ser uma espécie adaptada a essas áreas, poderá ser utilizada como uma das espécies no restabelecimento de matas ciliares.

O fósforo da planta encontra-se em cinco grupos: DNA (ácido desoxirribonucléico), o RNA (ácidos ribonucléicos), polímeros de nucleotídios, ésteres e Pi (fósforo inorgânico) (MALAVOLTA et al., 1997). Embora sendo classificado como macronutriente, os seus teores nas plantas são mais baixos que o nitrogênio e o potássio. Em quantidades adequadas, ele estimula o desenvolvimento radicular, é essencial para a boa formação da planta e incrementa a produção (RAIJ, 1991).

O objetivo do experimento foi avaliar o efeito de diferentes doses de fósforo no crescimento, produção de matéria seca e acúmulo de N, P, K, Ca, Mg e S em mudas de andiroba cultivadas em solo de várzea.

\section{MATERIAL E MÉTODOS}

O experimento foi conduzido em casa de vegetação do Departamento de Ciências do Solo (DCS) da Universidade Federal de Lavras (UFLA). Utilizou-se como substrato solo de várzea, cuja caracterização química e física se encontra na Tabela 1 . O delineamento experimental utilizado foi em blocos casualizados, com cinco repetições e quatro doses de fósforo $\left(0,150,300\right.$ e $450 \mathrm{mg} \mathrm{dm}^{-3}$ de P). A unidade experimental foi constituída por vasos, contendo 8 $\mathrm{dm}^{3}$ de solo, com uma planta por vaso. A fonte de fósforo utilizada nos tratamentos foi o MAP (fosfato monoamônico). 
Tabela 1 - Resultado das análises química e física do solo utilizado no experimento

Table 1 - Result of the chemical and physical analysis of the soil used on the experiment

\begin{tabular}{|c|c|c|c|c|c|c|c|c|c|c|c|c|c|c|c|}
\hline $\begin{array}{c}\mathrm{pH} \\
\mathrm{H}_{2} \mathrm{O}\end{array}$ & $\begin{array}{l}\mathrm{P} \quad \mathrm{K} \\
\mathrm{mg} / \mathrm{dm}^{3}\end{array}$ & $\mathrm{Ca}$ & $\begin{array}{r}\mathrm{Mg} \\
\mathrm{cm}\end{array}$ & $\begin{array}{l}\mathrm{Al} \\
/ \mathrm{dm}^{3}\end{array}$ & $\mathrm{l}+\mathrm{H}$ & $\begin{array}{c}\mathrm{MO} \\
\mathrm{dag} / \mathrm{kg}\end{array}$ & $\mathrm{Zn}$ & $\mathrm{Fe}$ & $\begin{array}{c}\mathrm{Mn} \\
\mathrm{mg} /\end{array}$ & $\begin{array}{l}\mathrm{Cu} \\
\mathrm{lm}^{3}\end{array}$ & & & \multicolumn{3}{|c|}{$\begin{array}{c}\text { Areia Silte Argila } \\
\text { dag } / \mathrm{Kg}\end{array}$} \\
\hline 1,4 & 12,8 & 2,7 & 1,0 & 2,4 & 12,9 & 6,3 & 6,4 & 58,0 & 31,5 & 0,7 & 0,7 & 12,3 & 24 & 44 & 32 \\
\hline
\end{tabular}

Classe textural: textura média

O fósforo, nas respectivas doses, foi misturado ao solo antes do enchimento dos vasos, e os demais nutrientes, utilizados para o balançeamento (Tabela 2), foram aplicados ao solo em dose única, com exceção do nitrogênio, que foi parcelado em duas aplicações. As sementes de andiroba foram postas para germinar, tendo vermiculita como substrato, e a umidade foi mantida com água deionizada. $\mathrm{O}$ transplantio ocorreu em agosto de 2001, com mudas medindo $8 \mathrm{~cm}$ de altura. A reposição de água nos vasos foi feita diariamente, mantendo-se a umidade em $60 \%$ do volume total de poros (VTP). As plantas foram colhidas após seis meses. Determinaram a altura $(\mathrm{cm})$ e diâmetro do caule $(\mathrm{mm})$, e, após a secagem em estufa de ventilação forçada de ar a $70^{\circ} \mathrm{C}$ até peso constante, foi determinada a matéria seca de raiz e parte aérea e total (g planta $\left.{ }^{-1}\right)$. Posteriormente, foi realizada a moagem do material para fins de análise química.

Através do extrato nítrico-perclórico foram determinados os teores de $\mathrm{P}$ por colorimetria, $\mathrm{Ca}$ e $\mathrm{Mg}$

Tabela 2 - Quantidades e fontes de adubos aplicados ao solo na adubação complementar

Table 2-Amounts and sources of fertilizers applied to the soil in the supplementary application of fertilizer

\begin{tabular}{l|c|c}
\hline Elementos & $\begin{array}{c}\text { Quantidade } \\
\left(\mathrm{mg} \mathrm{dm}^{-3} \text { de solo }\right)\end{array}$ & Fontes de adubo \\
\hline Potássio & 300,0 & $\mathrm{KCl}$ \\
Nitrogênio & 300,0 & $\mathrm{MAP} /$ Uréia \\
Magnésio & 60,0 & $\mathrm{MgSO}_{4}$ \\
Cálcio & 100,0 & $\mathrm{CaSO}_{4}$ \\
Boro & 0,5 & $\mathrm{H}_{3} \mathrm{BO}_{3}$ \\
Cobre & 1,5 & $\mathrm{CuSO}_{4} \cdot 5 \mathrm{H}_{2} \mathrm{O}$ \\
Molibdênio & 0,1 & $\left(\mathrm{NH}_{4}\right)_{6} \mathrm{Mo}_{7} \mathrm{O}_{24} \cdot 4 \mathrm{H}_{2} \mathrm{O}$ \\
Zinco & 5,0 & $\mathrm{ZnSO}_{4} \cdot 7 \mathrm{H}_{2} \mathrm{O}$ \\
\hline
\end{tabular}

por espectrofotometria de absorção atômica, K por fotometria de chama e de S por turbidimetria do sulfato de bário (MALAVOLTA et al., 1997). Os teores de N total foram determinados pelo método semimicro Kjeldahl (MALAVOLTA et al., 1997). A partir desses teores, determinou-se o acúmulo dos nutrientes com base na matéria seca. Os dados foram submetidos à análise estatística de regressão pelo programa Sisvar (FERREIRA, 2000).

\section{RESULTADOS E DISCUSSÃO}

Como mostrado na Tabela 1, originalmente o solo apresentava $12 \mathrm{mg} \mathrm{dm}^{-3} \mathrm{de}$ P. Assim, as plantas tiveram o suprimento mínimo de fósforo que proporcionou sua sobrevivência.

Pelos resultados apresentados nas figuras anteriores, pode-se observar que, em todas as medidas analisadas (diâmetro do caule, altura de plantas, matéria seca de raiz, parte aérea e total), o comportamento da resposta à adubação fosfatada foi quadrático, ou seja, houve uma resposta positiva incrementando essas medidas à proporção que aumentaram as doses de fósforo aplicadas ao solo, e, a partir de doses maiores, a resposta à adubação passou a decrescer.

A dose de $265 \mathrm{mg} \mathrm{dm}^{-3}$ de $\mathrm{P}$ proporcionou a obtenção do máximo diâmetro do caule (Figuras 1 e 5), em plantas de andiroba. Quanto à altura de plantas (Figura 2), a dose que proporcionou a máxima eficiência física foi de $239 \mathrm{mg} \mathrm{dm}^{-3}$ de P. A matéria seca de raiz (Figura 4) e parte aérea (Figura 3) apresentou máximas produções com as doses de 246 e $255 \mathrm{mg} \mathrm{dm}^{-3}$ de $P$, respectivamente.

De forma geral, todas as medidas estudadas apresentaram comportamento muito semelhante, apresentando seus pontos de máxima eficiência física entre 239 e $265 \mathrm{mg} \mathrm{dm}^{-3}$ de P. Foi observado du- 


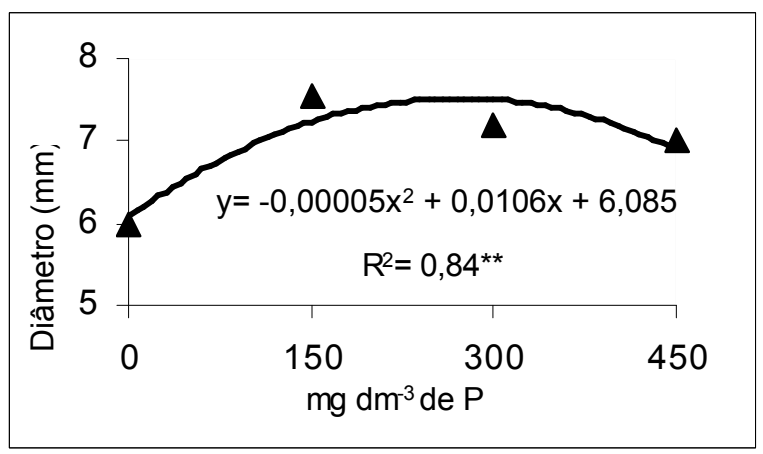

Figura 1 - Diâmetro do caule ( $\mathrm{mm}$ ) de mudas de andiroba cultivadas em solo de várzea, em função de doses de fósforo.

Figure 1-Stem diameter of stem ( $\mathrm{mm}$ ) of andiroba seedlings cultivated in lowland soil, in function of phosphorus doses.

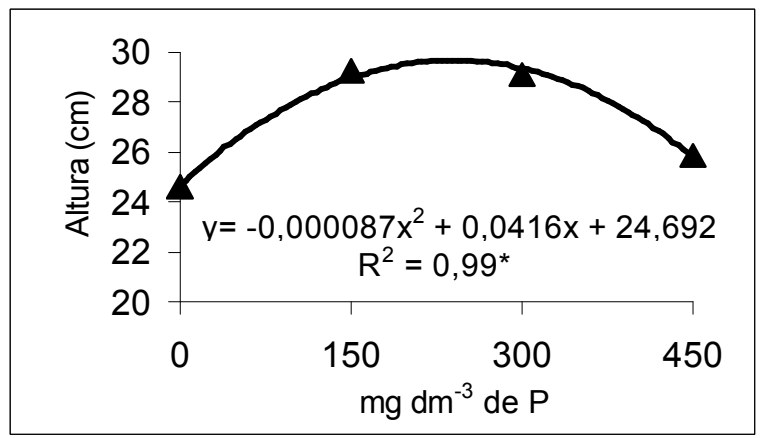

Figura 2 - Altura (cm) de mudas de andiroba cultivadas em solo de várzea, em função de doses de fósforo.

Figure 2-Height (cm) of andiroba seedlings cultivated in lowland soil, in function of phosphorus doses.

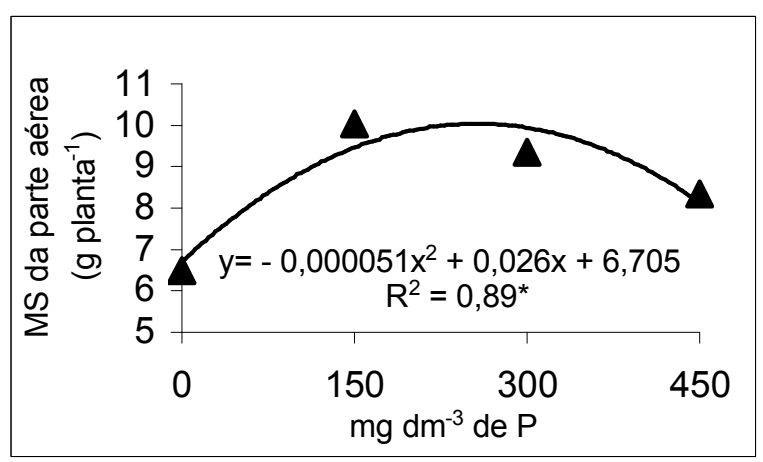

Figura 3 - Matéria seca da parte aérea de plantas de andiroba cultivadas em solo de várzea, em função de doses de fósforo.

Figure 3-Shoot dry matter of the of andiroba seedlings cultivated in lowland soil, in function of phosphorus doses.

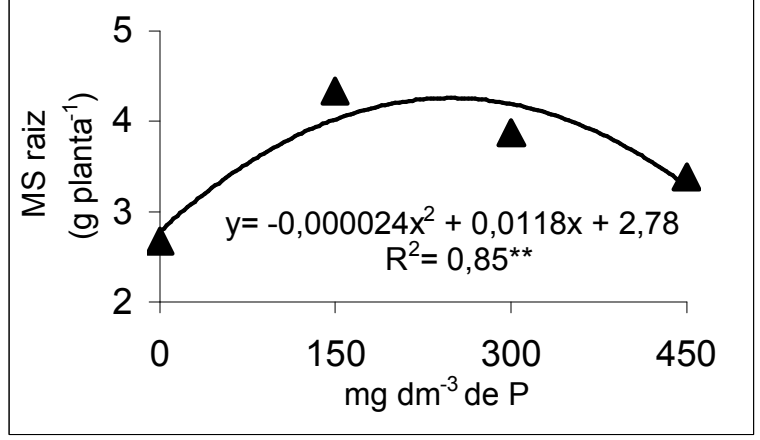

Figura 4 - Matéria seca de raiz de plantas de andiroba cultivadas em solo de várzea, em função de doses de fósforo.

Figure 4-RootDry matter of of andiroba seedlings cultivated in lowland soil, in function of phosphorus doses.

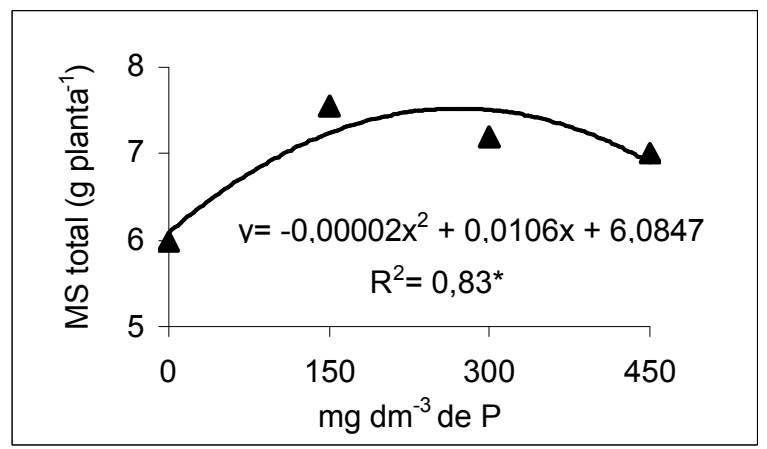

Figura 5 - Matéria seca total de plantas de andiroba cultivadas em solo de várzea, em função de doses de fósforo.

Figure 5-Dry matter total of andiroba seedlings cultivated in lowland soil, in function of phosphorus doses.

rante a condução do experimento que nas doses mais altas de fósforo ( $300 \mathrm{e} 450 \mathrm{mg} \mathrm{dm}^{-3} \mathrm{de} \mathrm{P}$ ), as plantas exibiram sintomas visuais de injúrias nas folhas, caracterizados por estrias amarelo-avermelhadas ao longo das nervuras. Sampaio (1998) descreveu a ocorrência de sintomas semelhantes em plantas de açaí, cultivadas em solo de várzea e submetidas à adubação fosfatada (doses acima de $300 \mathrm{mg} \mathrm{dm}^{-3} \mathrm{de} \mathrm{P).} \mathrm{A}$ ocorrência dessas injúrias possivelmente foi devida à diminuição da absorção de ferro e zinco nas doses mais elevadas de fósforo no solo. Efeitos antagôni$\cos$ entre o $\mathrm{P}$ e o $\mathrm{Fe}$, em que a aplicação de fósforo ao solo reduz a disponibilidade de zinco, foram relatados por Gupta (1982). Entre P e Zn, Singh e Singh (1980) verificaram a inibição da absorção de zinco por 
plantas de arroz quando adubadas com doses altas de fósforo. O mesmo efeito também já foi relatado em espécies florestais.

Também com relação ao acúmulo de N, P, K, Ca, Mg e S, observou-se um comportamento de resposta quadrático, como ilustram as figuras citadas. As plantas responderam à aplicação de fósforo com o incremento inicial no acúmulo dos elementos estudados e, a partir de doses maiores, a resposta à adubação passou a decrescer.

No nitrogênio (Figura 6), a dose de $254 \mathrm{mg} \mathrm{dm}^{-3} \mathrm{de}$ $\mathrm{P}$ propiciou maior acúmulo desse elemento na parte aérea das plantas de andiroba. No caso do fósforo (Figura 7), a obtenção do máximo acúmulo foi alcançada com a dose de $287,5 \mathrm{mg} \mathrm{dm}^{-3} \mathrm{de}$ P. Isso se deveu ao fato de que, em doses maiores de fósforo, o crescimento das plantas foi comprometido; assim, as mudas de andiroba apresentaram menor acúmulo de fósforo na parte aérea. A dose de $244,5 \mathrm{mg} \mathrm{dm}^{-3}$ de $\mathrm{P}$ promoveu o máximo acúmulo de potássio (Figura 8).

O máximo acúmulo de cálcio (Figura 9), magnésio (Figura 10) e enxofre (Figura 11) foram alcançados com as doses de 254, 241 e $275 \mathrm{mg} \mathrm{dm}^{-3}$ de P, respectivamente. Excetuando as doses de 275 e 287,5 $\mathrm{mg} \mathrm{dm}^{-3} \mathrm{de} \mathrm{P}$, que proporcionaram o máximo acúmulo de enxofre e fósforo na parte aérea das mudas de andiroba, as demais doses apresentaram um intervalo pequeno (241 a $254 \mathrm{mg} \mathrm{dm}^{-3}$ de P) entre elas para atingir o máximo

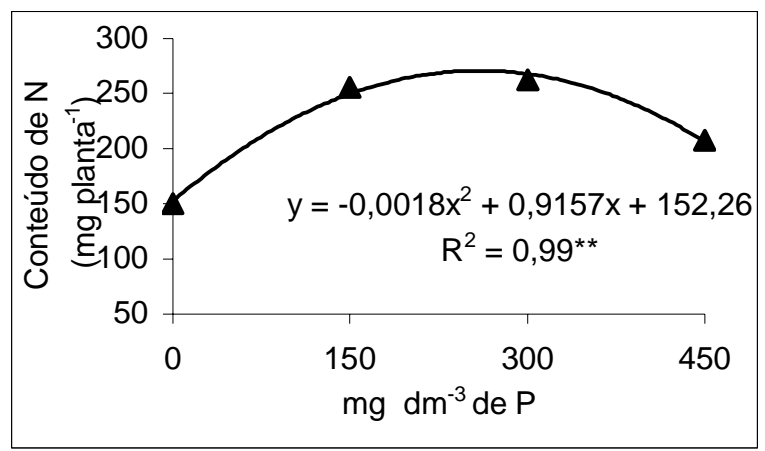

Figura 6 - Conteúdo de $\mathrm{N}\left(\mathrm{mg} \mathrm{planta}^{-1}\right)$ na parte aérea de mudas de andiroba cultivadas em solo de várzea, em função de doses de fósforo.

Figure 6- Accumulation $N\left(\right.$ mg plant $\left.^{-1}\right)$ in andiroba seeddling shoot cultivated in lowland soil, in function of phosphorus doses. acúmulo dos demais nutrientes estudados nas mudas.

Os elementos em estudo que mais se acumularam na parte aérea das mudas de andiroba seguem a seguinte ordem decrescente: $\mathrm{N}\left(254,3 \mathrm{mg} \mathrm{planta}^{-1}\right)>$ Ca $\left(133,5\right.$ mg planta $\left.^{-1}\right)>\mathrm{K}\left(106,5 \mathrm{mg}\right.$ planta $\left.^{-1}\right)>\mathrm{Mg}$ $\left(17,9 \mathrm{mg} \mathrm{planta}^{-1}\right)>\mathrm{S}\left(16,3 \mathrm{mg}\right.$ planta $\left.{ }^{-1}\right)>\mathrm{P}(6,4 \mathrm{mg}$ planta $\left.^{-1}\right)$. Trabalhando com andiroba em solução nutritiva, Martins et al. (2000) relataram que as maiores reduções no crescimento foram provocadas pela omissão na ordem decrescente de: $\mathrm{N}$ e $\mathrm{Ca}>\mathrm{Mg}>\mathrm{K}>\mathrm{P}>\mathrm{S}$, em macronutrientes.

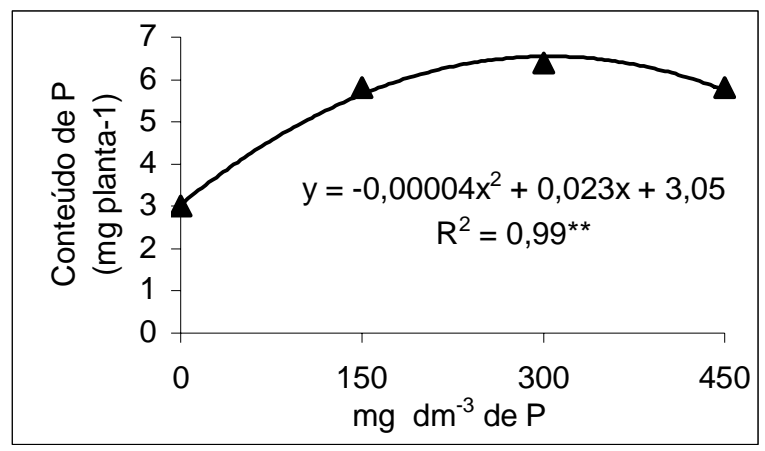

Figura 7 - Conteúdo de $\mathrm{P}\left(\mathrm{mg}_{\text {planta }}{ }^{-1}\right)$ na parte aérea de mudas de andiroba cultivadas em solo de várzea, em função de doses de fósforo.

Figure 7-Accumulation P ( $\left.\mathrm{mg} \mathrm{plant}^{-1}\right)$ in andiroba seedling shoot cultivated in lowland soil, in function of phosphorus doses.

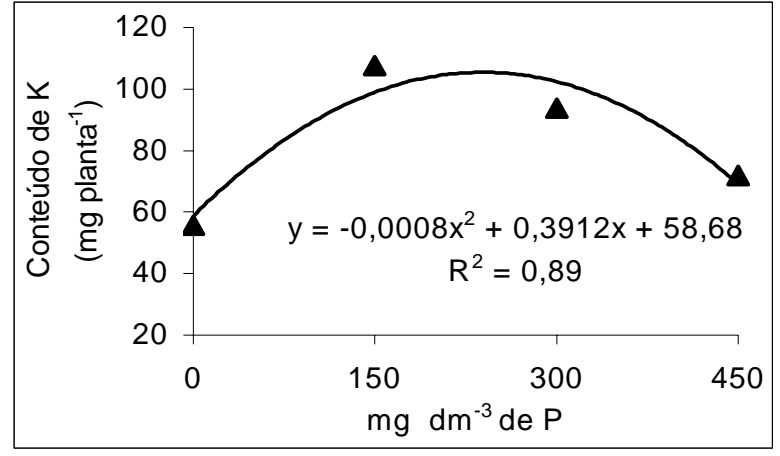

Figura 8 - Conteúdo de K (mg planta ${ }^{-1}$ ) na parte aérea de mudas de andiroba cultivadas em solo de várzea, em função de doses de fósforo.

Figure 8-Accumulation of K ( mg plant $\left.^{-1}\right)$ in andiroba seedling shoot cultivated in lowland soil, in function of phosphorus doses.

R. Árvore, Viçosa-MG, v.28, n.3, p. 343-349, 2004 


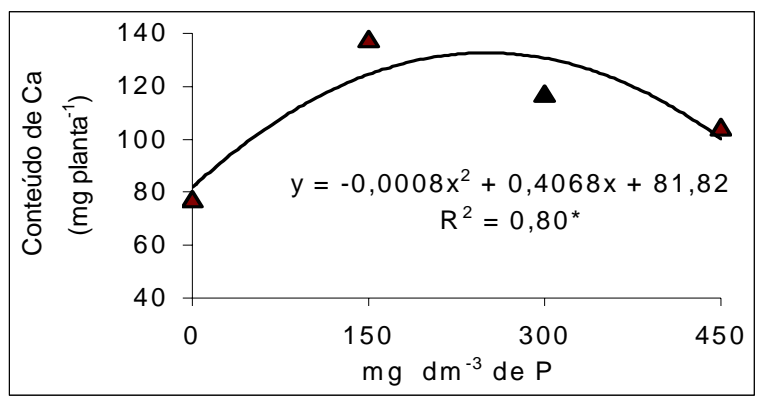

Figura 9 - Conteúdo de Ca (mg planta $\left.{ }^{-1}\right)$ na parte aérea de mudas de andiroba cultivadas em solo de várzea, em função de doses de fósforo.

Figure 9- Accumulation Ca ( mg plant $\left.^{-1}\right)$ in andiroba seedling shoot cultivated in lowland soil, in function of phosphorus doses.

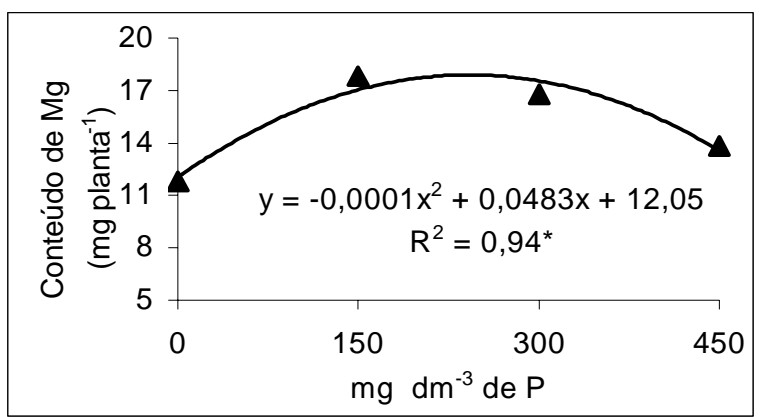

Figura 10 - Conteúdo de $\mathrm{Mg}$ (mg planta ${ }^{-1}$ ) na parte aérea de mudas de andiroba cultivadas em solo de várzea, em função de doses de fósforo.

Figure 10 - Accumulation $\mathrm{Mg}\left(\mathrm{mg} \mathrm{plant}^{-1}\right)$ in andiroba seeding shoot cultivated in lowland soil, in function of phosphorus doses

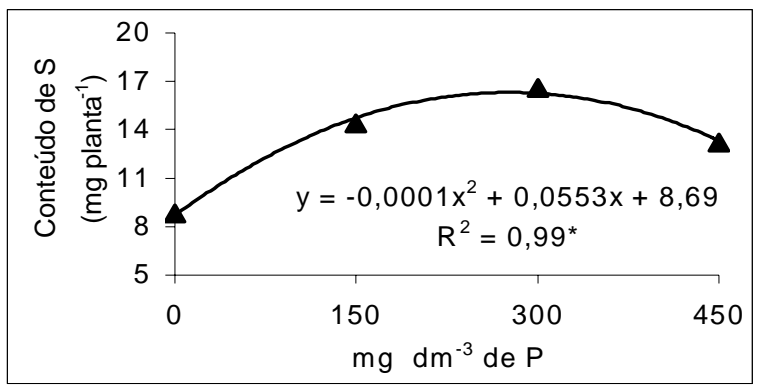

Figura 11 - Conteúdo de S (mg planta-1) na parte aérea de mudas de andiroba cultivadas em solo de várzea, em função de doses de fósforo.

Figure 11- Accumulation S ( $\mathrm{mg} \mathrm{plant}^{-1}$ ) in andiroba seeding shoot cultivated in lowland soil, in function of phosphorus doses.
Apesar de ser o macronutriente menos exigido em quantidade pelas plantas, o fósforo é o nutriente aplicado em maiores quantidades em adubação no Brasil. Furtini Neto et al. (2001) explicaram que esse fato se relacionava com a baixa disponibilidade de fósforo nos solos brasileiros e, também, com a forte tendência do fósforo aplicado ao solo de reagir com componentes deste para formar compostos de baixa solubilidade (fixação de fósforo).

Segundo Marschner (1995), o requerimento de fósforo para otimizar o crescimento da maioria das culturas está na faixa de 3 a $6 \mathrm{~g} \mathrm{~kg}^{-1}$ do peso de matéria seca de plantas durante o estádio vegetativo de crescimento. Malavolta et al. (1997) apresentaram valores na faixa de 1,2 a $4,0 \mathrm{~g} \mathrm{~kg}^{-1}$, na maioria das culturas tropicais. Como verificado neste estudo, o fósforo na parte aérea de mudas de andiroba, na sua máxima produção física, foi de $0,64 \mathrm{~g} \mathrm{~kg}^{-1}$ da matéria seca da parte aérea, ficando, assim, abaixo das faixas mencionadas pelos autores supracitados. É interessante ressaltar que, no caso das mudas de andiroba, realizou-se a análise de toda a parte aérea, e os valores referidos por esses autores são de análise de folhas. Tais resultados apontam para uma alta eficiência na utilização do fósforo por plantas de andiroba.

\section{CONCLUSÕES}

1 - A dose de $240 \mathrm{mg} \mathrm{dm}^{-3}$ de P é indicada para a produção de mudas de andiroba.

2 - A ordem decrescente de acúmulo de macronutrientes na parte aérea de mudas de andiroba é: $\mathrm{N}$ $>\mathrm{Ca}>\mathrm{K}>\mathrm{Mg}>\mathrm{S}>\mathrm{P}$.

\section{REFERÊNCIAS BIBLIOGRÁFICAS}

DELDUQUE, E. Ficha da planta - Andiroba. Revista Globo Rural, Rio de Janeiro: 1999. 169 p.

FERREIRA, D. F. Análises estatísticas por meio do SISVAR (Sistema para Análise de Variância) par Windows 4.0. In: REUNIÃO ANUAL DA REGIÃO BRASILEIRA DA SOCIEDADE INTERNACIONAL DE BIOMETRIA, 45., 2000, São Carlos. Anais... São Carlos: UFSCAr, 2000. p. 255-258.

FURTINI NETO, A. E. et al. Fertilidade do solo. Lavras: UFLA/FAEP, 2001. 252 p. 
GUPTA, R. K. et al. Effect of phosphorus application on the transformation of iron in soil and iron nutrition of rice under two soil moisture regimes. Journal Indian Society Soil Science, v. 30, n. 1, p. 58 - 62, 1982.

LOUREIRO, A. A.; SILVA, M. F.; ALENCAR, J. C. Essências madereiras da Amazônia. Manaus: CNPq/INPA/SUFRAMA. Boletim de Pesquisa, v. 1, p. 245, 1979.

MAGALHÃES, L. M. S.; BLUM, W. E. H.; FERNANDES, N. P. Características edáficonutricionais de Carapa guianensis Aubl. Em solos de diferentes texturas. Acta Amazônica, v. 16/17, p. 523 - 534, 1987.

MALAVOLTA, E.; VITTI, G. C.; OLIVEIRA, S. A. Avaliação do estado nutricional das plantas: princípios e aplicações. 2. ed. Piracicaba: POTAFOS, 1997. 319 p.

MARSCHNER, H. Mineral nutrition of higher plants. 2. ed. London: Academic Press, 1995. $889 \mathrm{p}$.

MARTINS, G. C. et al. Efeito da omissão de micronutrientes no crescimento de mudas de andiroba (Carapa guianensis Aubl.). Anais da FERTBIO 2000. Santa Maria: [s.n], 2000a. $214 \mathrm{p}$.

MARTINS, G. C. et al. Efeito da omissão de macronutrientes no crescimento de mudas de andiroba (Carapa guianensis Aubl.). Anais da FERTBIO 2000. Santa Maria: [s.n], 2000b. 177p.
NEVES, O. S. C. et al. Efeito de diferentes doses de fósforo no crescimento e produção de matéria seca de mudas de andiroba (Carapa guianensis) cultivadas em solo de várzea. Anais da FERTBIO 2002. Rio de Janeiro: [s.n.] 2002. p. 88.

RAIJ, B. van. Fertilidade do solo e adubação. 2. ed. Piracicaba: Ceres, 1991. 343 p.

RASSINI, J. B. et al. Caracterização de várzeas nas regiões dos cerrados. Planaltina: EMBRAPA-CPAC, 1984. 16 p. (EMBRAPA-CPAC - Boletim de Pesquisa, 22).

SAMPAIO, L. S. Resposta de plantas jovens de açaí à adubação fosfatada e à inundação em solos de várzea. 1997. 150 f. Dissertação (Mestrado em Solos e Nutrição de Plantas) - Universidade Federal de Lavras, Lavras, 1997.

SANTOS, M. N. et al. Produção de matéria seca de andiroba (Carapa guianensis) em função de doses de Mn em solução nutritiva. Anais da FERTBIO 2002. Rio de Janeiro: [s.n.], 2002. p. 89.

SINGH, M.; SINGH, S. P. Zinc and phosphorus interaction in submerged paddy. Soil Science, v. 129, n. 3, p. 171 - 180, 1980.

VOLPATO, E.; SCHMIDT, P.B.; ARAÚJO,V.C. Carapa guianensis Aubl. (Andiroba). Estudos comparativos de tratamentos silviculturais. Acta Amazônica, v. 2, n. 3, p. 75 - 81, 1972.

VOLPATO, E.; SCHMIDT, P.B.; ARAÚJO,V. C. Situação dos plantios comerciais na Reserva Florestal Ducke. Acta Amazônica, v. 3, n. 1, p. 71- 82, 1973. 